\title{
Global expressions for seasonal temperatures of the sea surface and ambient air - the influence of tidal currents and water depth
}

\section{David PRANDLE}

Proudman Oceanographic Laboratory, Bidston Observatory, Birkenhead, Merseyside L43 7RA, U.K.

(Received 15/11/96, revised 18/11/97, accepted 25/11/97)

\begin{abstract}
A 'single point' coupled ocean-atmosphere model is formulated to study seasonal temperature cycles with particular application to shelf seas. The simplified atmospheric module is consistent with the physical processes described by Gill [4] while the vertical exchange of heat in the ocean module is determined via a turbulence closure model. The various empirical coefficients in the atmospheric module were determined by fitting the model output to North Atlantic observational data over the latitude range $0^{\circ}$ to $65^{\circ} \mathrm{N}$. The model is then applied to the shallow, strongly tidal North Sea. The general validity of the model is demonstrated, thereby indicating that the seasonal cycles of the sea surface, $T_{s}$, and ambient air, $T_{a}$, are generally governed by a localised equilibrium. In shallow water $(<200 \mathrm{~m})$ the amplitude of this seasonal cycle is modulated by both the water depth and tidal current amplitude. North Sea observational data confirm these model indications that large tidal currents decrease seasonal amplitudes. This study provides, for the first time, a quantitative estimate of this influence of shallow seas on adjacent coastal climates.

It is shown how the model results can be sensibly approximated by generalised expressions - illustrating that mean valucs of both $T_{s}$ and $T_{a}$ vary with the cosine of latitude (up to $65^{\circ} \mathrm{N}$ ) while their seasonal amplitudes vary directly with latitude and inversely with an exponent of water depth. Thus these generalised expressions can be conveniently used to provide boundary conditions in generalised ecological models. The model can also be used for (small amplitude) sensitivity analyses to examine, for example, the effect of changes in storminess or cloud cover. (C) Elsevier, Paris
\end{abstract}

\section{temperature / annual cycle / atmosphere-ocean coupling / shelf seas / North Sea}

Résumé -- Expressions globales des températures saisonnières de l'eau et de l'air - effet des courants de marée et de la profondeur d'eau. Un modèle couplé océan-atmosphère est proposé pour simuler les cycles annuels des températures, en particulier dans les mers bordières. Le module atmosphérique simple est en accord avec les phénomènes physiques décrit par Gill [4] tandis que, dans le module océanique, le transfert thermique vertical est déterminé par un modèle turbulent de fermeture. Les coefficients empiriques du module atmosphérique sont déterminés par ajustement aux données collectées dans le nord de l'Atlantique, entre $0^{\circ}$ et $65^{\circ} \mathrm{N}$ de latitude. Le modèle est ensuite appliqué à une mer peu profonde et soumise à de fortes marées, la mer du Nord. La validité générale du modèle étant démontrée, les cycles saisonniers de la température superficielle de l'eau $T_{s}$ et de celle de l'air ambiant $T_{a}$ sont généralement déterminés par un équilibre local. Par mer peu profonde (moins de $200 \mathrm{~m}$ ) l'amplitude du cycle saisonnier est modulée à la fois par la profondeur d'eau et par l'amplitude du courant de marée. Les observations en mer du Nord, confirmant les résultats du modèle, indiquent que les forts courants de marée atténuent l'amplitude des variations saisonnières. Le présent travail est le premier à donner une estimation quantitative de l'effet des mers peu profondes sur le climat des régions côtières voisines. Les résultats du modèle peuvent être approchés par des expressions généralisées montrant que les valeurs moyennes des températures $T_{s}$ et $T_{a}$ sont proportionnelles au cosinus de la latitude (jusqu'à $65^{\circ} \mathrm{N}$ ) tandis que l'amplitude de leurs variations saisonnières est directement proportionnelle à la latitude et fonction inverse d'une puissance de la profondeur d'eau. Ces expressions générales peuvent fournir les conditions aux limites dans des modèles écologiques globaux. Le modèle peut également être utilisé dans les analyses de sensibilité (petites amplitudes) pour examiner par exemple l'effet des conditions orageuses, de la nébulosité, etc. @ Elsevier, Paris

température / cycle annuel / couplage océan-atmosphère / mer bordière / mer du Nord 


\section{INTRODUCTION}

The description of temperature in marine ecological models is important both directly via its influence on specific parameters and indirectly via its contribution to vertical density variations. Recent studies of temperature distributions in shelf seas have successfully reproduced the seasonal cycle $[2,14]$ and aspects of inter-annual variability $[7,11]$. It is of interest to use such models to conduct sensitivity tests examining, for example, impacts on seasonal temperatures of changes in wind speed or water constituents (on the surface reflectance and internal absorption of solar radiation). However, a major limitation in such studies is the prescription of fixed air temperature, eliminating the feed-back impact of changes in sea temperature on ambient air temperature.

Clearly there is a close thermal coupling between the atmosphere and the sea with characteristic cycles at daily, monthly and semi-monthly (spring-neap tides) and annual frequencies. The objective of the present study was to formulate a coupled air-sea thermal exchange model, concentrating on reproduction of the annual temperature cycle of the sea surface and ambient air.

Section 2 describes the features of both the atmospheric and ocean modules. More detailed formulations are provided in four appendices outlining: 1. the Ocean Model; 2. the Atmospheric Model; 3. Air-Sea Thermal Exchanges and 4. the Turbulence Model. Figure 1 provides a schematic representation of the thermal exchanges and table $I$ lists the related parameters and their specified values.

Section 3 describes model simulations of the seasonal thermal cycle over a range of latitudes, water depths and tidal current speeds. The semi-empirical coefficients in the atmospheric model were derived by fitting these model results to observational data from the North Atlantic. In Section 4, the validity of this coupled model is then assessed by application to the North West European Shelf Seas involving comparisons with observed values for the seasonal cycle of both sea surface and ambient air temperatures.

\section{THE OCEAN-ATMOSPHERE MODEL}

The atmospheric module developed here is effectively the simplest possible to incorporate air-sea thermal exchanges. The salient features are indicaled in figure 1 and table I; detailed descriptions are presented in appen-

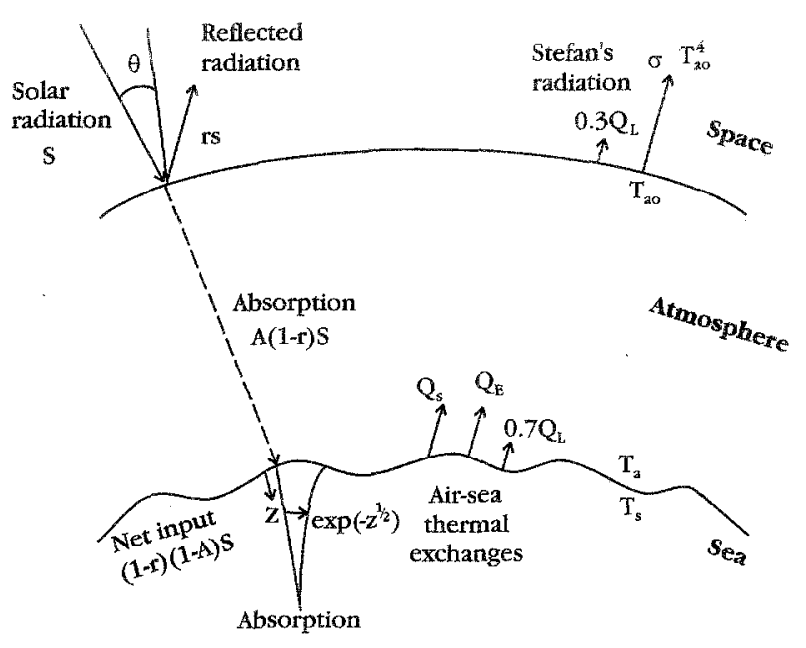

Figure 1. Schematic representation of atmosphere-ocean themal exchange model.

dices 1 to 4 . Incident solar radiation is modulated by a reflection coefficient at the outer edge of the atmosphere and thence by internal absorption. The external heat loss rate from the atmosphere follows Stefan's law.

This atmospheric model is linked to an oceanic model with air-sea exchange rates from Gill [4], comprising long wave radiation, evaporation and convection (or sensible heat flux). Vertical exchange within the water column is governed by both tidal and wind forced turbulent intensity levels, modulated by vertical density gradients. A Mellor-Yamada [9] level 2.5 turbulence closure model is used to incorporate these effects. Nunes Vaz and Simpson [10] illustrate the efficiency of this scheme in reproducing tidally modulated stratification in shallow water. The atmospheric model effectively forms a 'surface layer' to the oceanic model with external boundary conditions (incident solar energy, radiated and reflected thermal energy) specified at the outer edge of the atmosphere.

The many coefficients incorporated in the model were derived in the course of the simulations described in the next section. The global mean value for the present formulation for the atmospheric reflection factor, $r$, (Eq. A.5) is 0.30, in precise agreement with Gill [4]. The formulation for the atmospheric absorption coefficient, $A=0.11$, corresponds to a global mean absorption factor of 0.15 (Appendix 2) while Gill estimated 0.19. From Appendix 2, the net solar radiation into the sea is $S(\cos \theta(1-r)-A)$, hence some flexibility exists between the respective formulations of $A$ and $r$. A latitudinal variability in $A$ could be introduced in the same manner as specified for $r$ in equation A.5. 
Table I. Model parameters

\begin{tabular}{llll}
\hline atmospheric reflection & $\begin{array}{l}r=-0.47 \\
+0.86(\cos \lambda)^{1 / 2}\end{array}$ & $\begin{array}{l}\text { atmospheric height } m \\
\text { (water depth equivalent) } \\
\text { relative humidity }\end{array}$ & $R=2.5$ \\
$\begin{array}{l}\text { ( } \lambda \text { latitude) } \\
\text { atmospheric absorption coefficient }\end{array}$ & $A=0.11$ & wind speed $\mathrm{m} \mathrm{s}^{-1}$ & \\
atmospheric temperature gradient & $\Delta T=42.5^{\circ} \mathrm{C}$ & $\left(\omega_{a}\right.$ annual cycle) & $W=6\left(1+(\lambda / 65)^{2}\right) x$ \\
cloud cover & $C=0.5$ & number of vertical grid points & $n=10$ to 100 \\
minimum vertical eddy diffusivity $\mathrm{m}^{2} \mathrm{~s}^{-1}$ & $\mathrm{~K}_{\mathrm{MIN}}=10^{-5}$ & time step & $\Delta t=900 \mathrm{~s}$
\end{tabular}

A fixed temperature difference, $\Delta T$, of $42.5^{\circ} \mathrm{C}$ is assumed between the sea surface and the outer edge of the atmosphere. The computed mean sea surface temperature, at any latitude, depends primarily on the prescriptions of $A$, $r$ and $\Delta T$. Their present derivation was by numerical experimentation during the simulations described in the following section, their incidental physical validity is encouraging.

\section{GLOBAL SIMULATIONS OF THE ANNUAL CYCLE OF AIR-SEA TEMPERATURES}

A series of simulations was made over a range of geographic (latitude and water depth) and tidal current conditions. The model simulations extended over a sufficient number of years $\omega$ achieve cyclical stability, independent of initial conditions. The model parameters listed in table $I$ were adjusted to reproduce seasonal temperature cycles of the sea surface and ambient air observed in the North $\Lambda$ tlantic (extracted by Isemer and Hasse [5] from Bunker's data).

The model was operated for: (i) latitudes, $\lambda$ from $5^{\circ}$ to $65^{\circ} \mathrm{N}$ in $10^{\circ}$ increments (the limit of $65^{\circ} \mathrm{N}$ avoids the anomalous density behaviour of water below freezing point) (ii) water depths, $D$ from 10 , to $1000 \mathrm{~m}$ increasing in nine proportional steps of 1.67 and (iii) tidal current amplitudes, $\hat{R}$ from 0.1 to $0.5 \mathrm{~m} \cdot \mathrm{s}^{-1}$ in $0.1 \mathrm{~m} \cdot \mathrm{s}^{-1}$ increments. A seasonal and latitudinal dependent description of wind speed, representative of North Atlantic conditions, was also incorporated (table I). These parameter ranges were used to represent a comprehensive range of conditions from shelf seas to ocean. The fitting of the model coefficients by reference to the North Atlantic observations only involved model results pertaining to $D=1000 \mathrm{~m}$ and $\hat{R}=0.1 \mathrm{~m} \cdot \mathrm{s}^{-1}$.

Figure 2 shows salient results for the annual mean temperatures, $\bar{T}_{s}, \bar{T}_{a}$. Equations (1) and (2) were derived from least squares fitting to these model results (Equations 1 to 6 are shown in table II). The figure shows comparisons against the observed mean temperatures from the Bunker Climate Atlas of the North Atlantic. These comparisons followed an iterative sequence of adjustment to the coefficients in the model. Mean temperatures are overwhelmingly determined by latitude, as indicated by equations 1 and 2 with little influence of water depth or tidal current amplitude.

Clearly a major limitation in the application of the model is the assumption of a localised equilibrium, i.e. neglect of horizontal advection of thermal energy. For the envisaged application of the model to shallow seas at mid-latitudes this assumption is often reasonably valid [18]. Latitudinal transfer of thermal energy by ocean currents involves a net local source of order $1 \mathrm{~W} \cdot \mathrm{m}^{-2},[3]$, compared with a global mean rate of incident solar energy of order $200 \mathrm{~W} \cdot \mathrm{m}^{-2}$. However, the complexity of ocean currents can produce localised enhancements and hence modify the results shown.

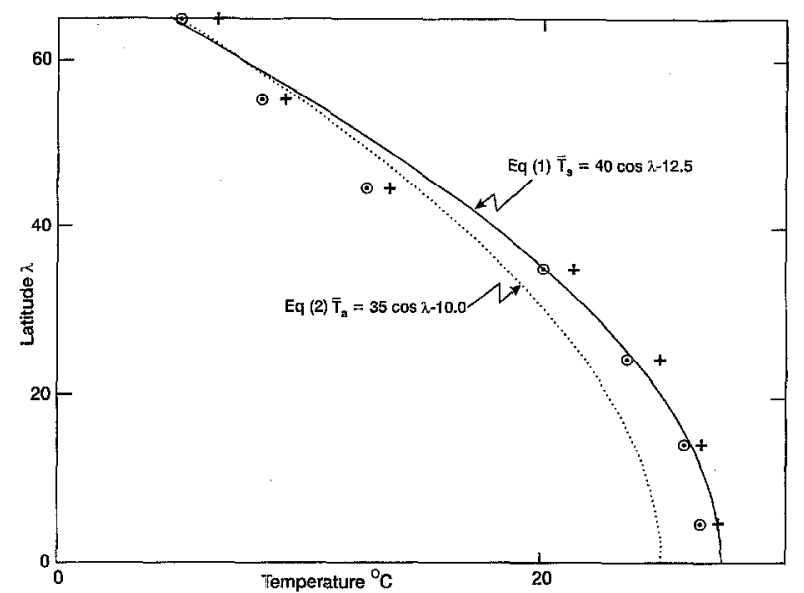

Figure 2. Computed annual mean temperatures: $\bar{T}_{S}$ sea surface, $\bar{T}_{a}$ ambient air. Bunker Atlas Observations: o air, + sea. 
Table II. Global expressions for the mean temperatures and seasonal amplitudes of the sea surface and ambient air.

\begin{tabular}{|c|c|c|c|c|}
\hline Means & Equ. No & PVA & $N$ & $\mathbf{R}\left(\mathrm{m} \mathrm{s}^{-1}\right)$ \\
\hline \multicolumn{5}{|l|}{ Sea surface } \\
\hline $\begin{array}{l}\bar{T}_{s}=40 \cos \lambda-12.5 \\
\text { ambient air }\end{array}$ & $(1)$ & 99 & 264 & 0.1 to 0.5 \\
\hline $\begin{array}{l}\bar{T}_{a}=35 \cos \lambda-10.0 \\
\text { seasonal amplitudes }\end{array}$ & (2) & 99 & 259 & 0.1 to 0.5 \\
\hline \multicolumn{5}{|l|}{ sea surface } \\
\hline$\hat{T}_{s}=0.080 \lambda /(1-\exp (-\mathrm{D} / 50))$ & (3) & 99 & 64 & 0.1 \\
\hline $\begin{array}{l}\hat{T}_{s}=0.064 \lambda /(1-\exp (-\mathrm{D} / 50)) \\
\text { ambient air }\end{array}$ & (4) & 89 & 200 & 0.2 to 0.5 \\
\hline$\hat{T}_{a}=0.086 \lambda /(1-\exp (-\mathrm{D} / 50))$ & $(5)$ & 99 & 63 & 0.1 \\
\hline$\hat{T}_{a}=0.067 \lambda /(1-\exp (-\mathrm{D} / 50))$ & (6) & 89 & 196 & 0.2 to 0.5 \\
\hline
\end{tabular}

$\lambda$ latitude, subscriptions $\mathrm{s}$ - sea surface; a - air, temperature in ${ }^{\circ} \mathrm{C}$

PVA percentage variance accounted for i.e. of model values shown in figure 2 by analytical expressions over parameter ranges $0^{\circ}<\lambda<65^{\circ}$ and depths $10<D<1000 \mathrm{~m}$ and current amplitudes $\hat{R}$ indicated.

$N$ Number of model data values in PVA calculation.

The agreements between model estimates for the seasonal amplitudes $\hat{T}_{s}$ and $\hat{T}_{a}$ (figures $3 a$ and $3 b$ ) are less close. However, since observed values for these parameters show considerable variability with longitude, no extensive effort was made to force a closer fit. The corresponding generalised expressions for $\hat{T}_{s}$ and $\hat{T}_{a}$, equations (3) to (6), were likewise derived from least squares fitting to the model results over the full range of both latitudes and depths. (Model results indicating $\hat{T}_{s}$ or $\hat{T}_{a}$ $>10{ }^{\circ} \mathrm{C}$ were excluded to avoid aliasing of the expressions by a few large values.) These expressions illustrate the linear dependence on latitude in combination with an exponential function of depth. The latter term increases $\overleftrightarrow{T}_{s}$ and $\widehat{T}_{a}$ dramatically in shallow water while progressively eliminating dependence on water depth, for $D \gg 100 \mathrm{~m}$. In water depths $D>40 \mathrm{~m}$, the values of both $\hat{T}_{s}$ and $\hat{T}_{a}$ increase significantly for the smallest value of tidal current amplitude $\hat{R}=0.1 \mathrm{~m} \cdot \mathrm{s}^{-1}$. However for $\hat{R} \geq 0.3 \mathrm{~m} \cdot \mathrm{s}^{-1}$ the values of both $\hat{T}_{s}$ and $\hat{T}_{a}$ converge asymptotically towards a minimum value. Note that for a 'free wave' $\hat{R} \approx \hat{\zeta}(g / D)^{1 / 2}$, thus for a typical oceanic condition of $\hat{\zeta}<0.5 \mathrm{~m}$ and $D>1000 \mathrm{~m}, \hat{R}<0.05 \mathrm{~m} \cdot \mathrm{s}^{-1}$; while for shelf seas where $\hat{\zeta}>1 \mathrm{~m}, D<75 \mathrm{~m}, \hat{R}>$ $0.3 \mathrm{~m} \cdot \mathrm{s}^{-1}$.

The phases for the seasonal cycles indicate that maximum northern hemisphere sea surface temperatures almost always occur between Julian days 230 and 255 generally earlier in deeper water (see [14] for a fuller explanation of these characteristics). The phases for air temperatures generally follow those of the sea surface with maximum temperatures typically five to ten days later. Spatial variations in these seasonal cycles may generate corresponding variations in mean sea level [13].

Sensitivity tests were made involving changes to all of the model parameters: $r, A, \Delta T, C, K_{\mathrm{MIN}}, d, R$ and $W$ listed in table $I$. A full account of these tests is beyond the
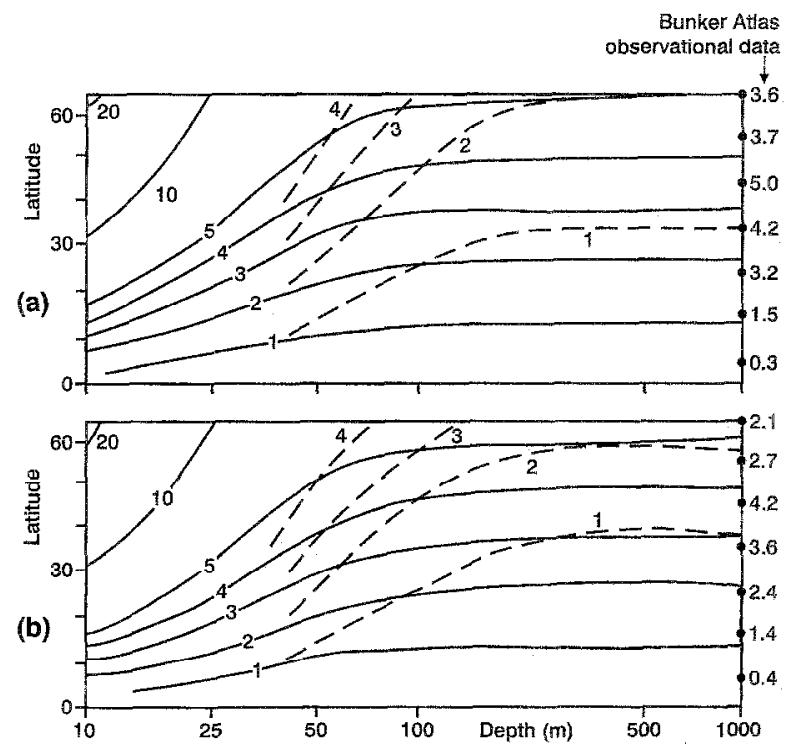

Figure 3. Computed seasonal temperature amplitudes $\left({ }^{\circ} \mathrm{C}\right)$.

(a) $\hat{T}_{s}$ sea surface; (b) $\hat{T}_{a}$ ambient air. $\hat{R}=0.1 \mathrm{~m} \mathrm{~s}^{-1}$; - - $\hat{R} \geq 0.2 \mathrm{~m} \mathrm{~s}^{-1}$. 
scope of this paper. Moreover, sensitivity tests involving perturbations in any one specific parameter may be misleading in so far as they neglect what in nature may involve accompanying changes in other parameters. However the robustness of the results presented here to $\pm 10 \%$ changes in these parameters was notable. This is an encouraging result for applications of the coupled model to such questions as the impact of extreme surge events, etc..

\section{NW EUROPEAN SHELF SEAS}

A test of the model's performance in shallow seas was made using observed air and sea surface temperatures for the NW European Shelf Seas together with depth and

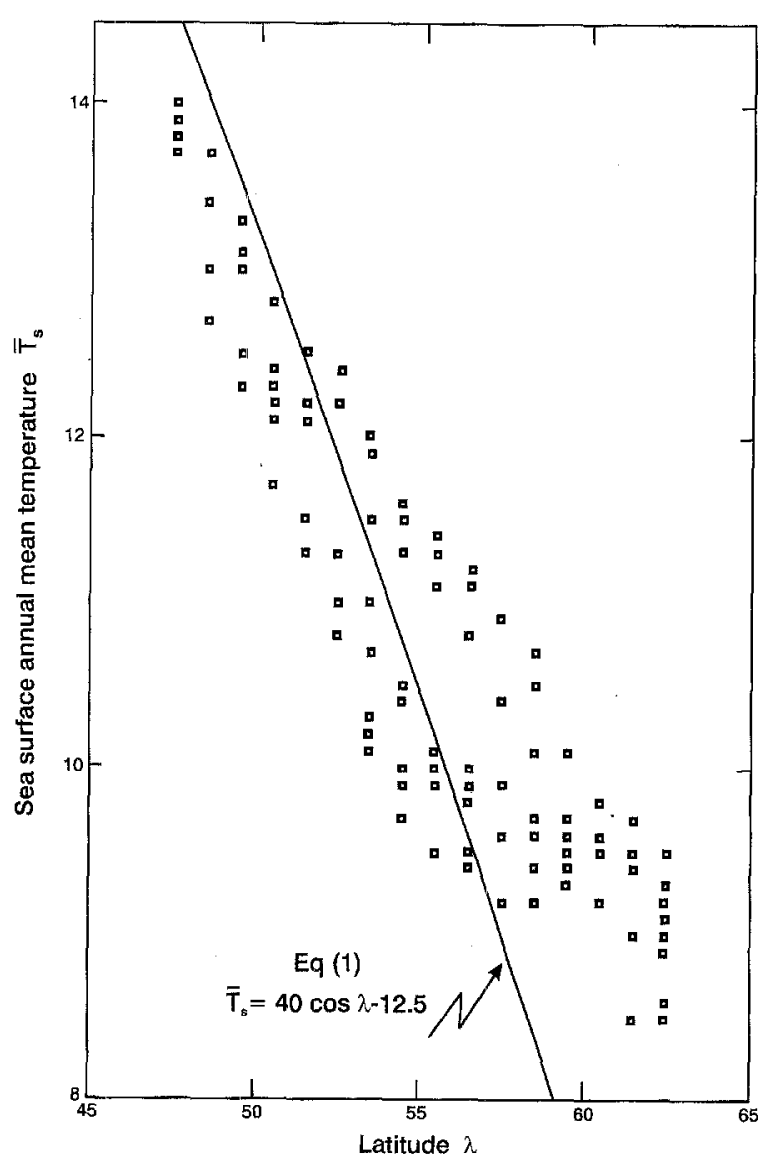

tidal current amplitudes from a $35 \mathrm{~km}$ grid numerical model [12].

Two observational data sets were used: one for sea surface temperatures was extracted from a 5 year set of monthly observations, from 1970 to 1974 , collated by ICES [15]. The second, for air temperature, applies to the North Sea only and was extracted from quarterly distributions [6].

Figures $4 a$ and $4 b$ show comparisons of these observational data against the generalised expressions (Equations 1 and 2) for the respective mean of sea surface temperature $\bar{T}_{s}$ and ambient air $\bar{T}_{a}$. The reasonable agreement shown substantiates the deduction that mean temperatures are primarily dependent on the cosine of latitude. The empirical formulations indicate slightly larger latitudinal gradients than the observations. This may be

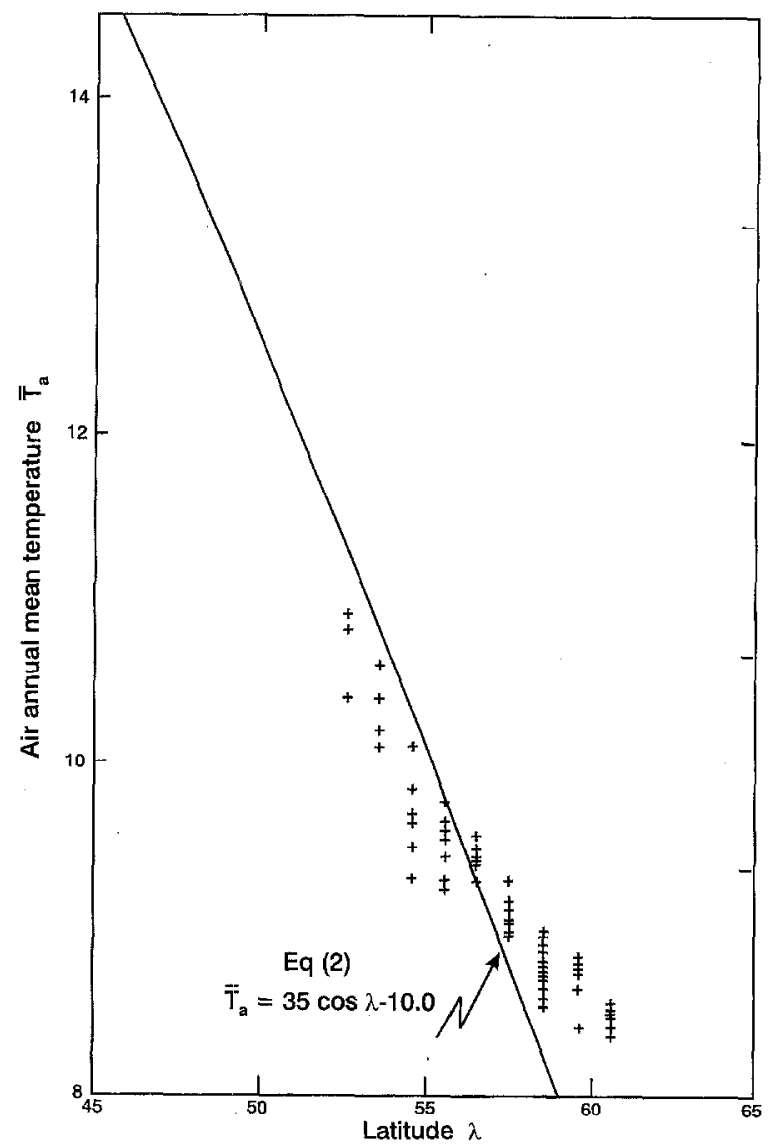

Figure 4. Annual mean temperatures over the N.W. European Shelf Seas (a) $\bar{T}_{s}$ sea surface; (b) $\bar{T}_{a}$ ambient air; - computed, ICES data, + Korevaar's data (N. Sea). 

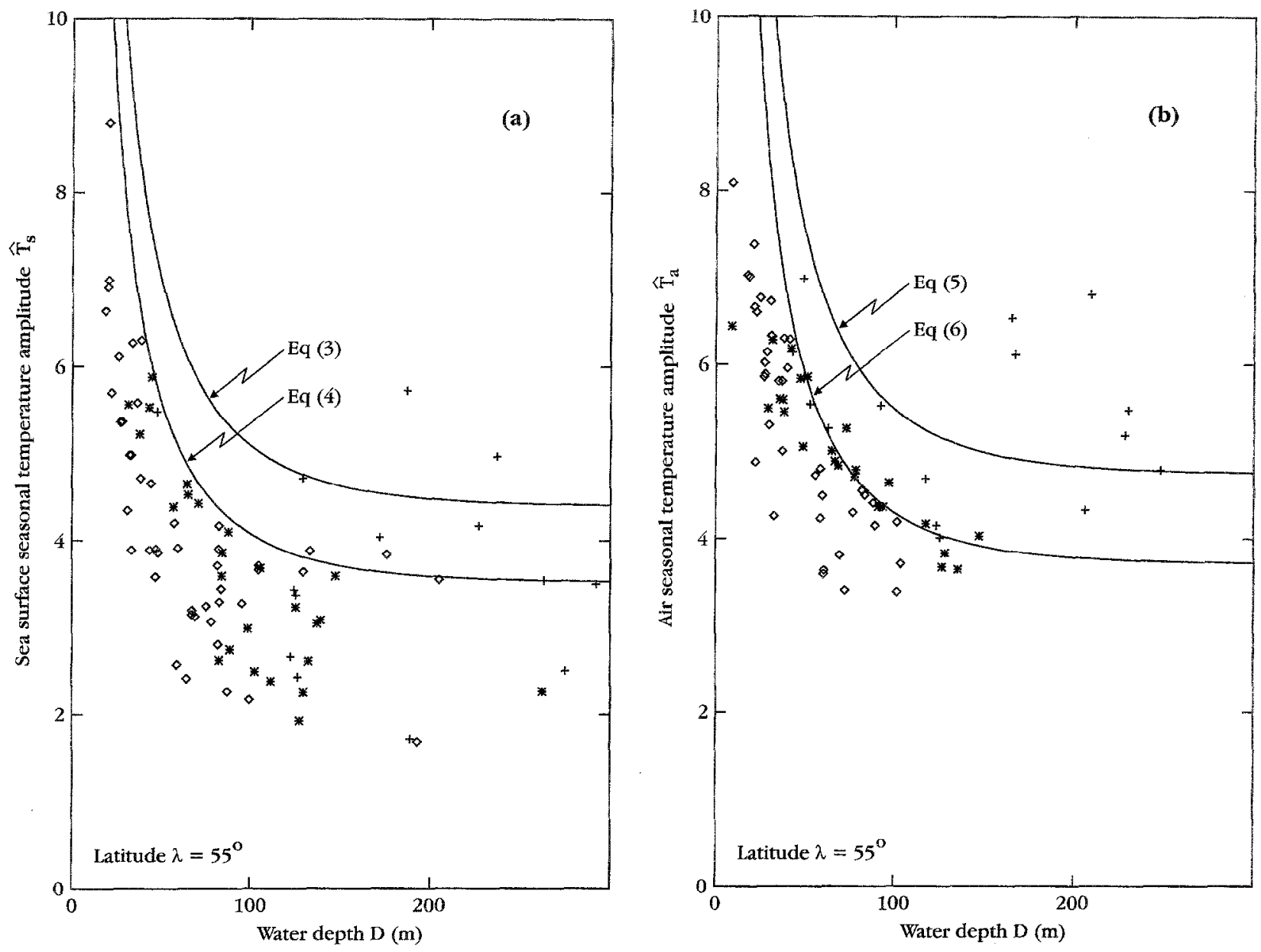

Figure 5. Seasonal temperature amplitudes.

(a) $\hat{T}_{s}$ sea surface; (b) $\hat{T}_{a}$ ambient air; ___ computed: (a) ICES data; (b) Korevaar's data.

$\hat{R}>0.3 \mathrm{~m} \mathrm{~s}^{-1} * 0.3>\hat{R}>0.15,+\hat{R}<0.15 \mathrm{~m} \mathrm{~s}^{-1}$

attributable to regional scale variabilities in $r, A, \Delta T$ or $C$ different from those assumed in table $I$.

Figures $5 a$ and $5 b$ show corresponding comparison for the seasonal amplitudes $\hat{T}_{s}$ and $\hat{T}_{a}$. In these figures, the observational results have been 'normalised' to latitude $55^{\circ} \mathrm{N}$ by scaling by $(55 / \lambda)$ to remove the linear dependence on latitude $\lambda$ indicated by equations (3) to (6). The model results were likewise calculated for $\lambda=55^{\circ} \mathrm{N}$. The distributions of the observed values of both $\hat{T}_{s}$ and $\hat{T}_{a}$ generally approximate the generalised expressions (improved 'fits' could be obtained by suitable adjustment of the model coefficients). To investigate the influence of tidal current amplitude indicated by the model, the observational data were separated into 3 categories according to tidal current amplitude $\hat{R}<0.15 \mathrm{~s}^{-1}, 0.15<$
$\hat{R}<0.3 \mathrm{~m} \cdot \mathrm{s}^{-1}$ and $\hat{R}>0.3 \mathrm{~m} \cdot \mathrm{s}^{-1}$. The segregation between each of these data sets and their respective generalised expressions substantiates the model result that seasonal amplitudes of both air and sea surface temperatures are modulated by tidal currents in shelf seas. This dependency of sea surface temperature in shelf seas on both $D$ and $\hat{R}$ has long been recognised (Simpson and Bowers [17], Prandle and Lane [14]) via the influence of thermal stratification. However the quantification of the corresponding influence on ambient air temperatures is a new result.

\section{CONCLUSIONS}

A simplified ocean-atmosphere thermal model has been developed for studying seasonal and inter-annual tempera- 
ture variability. The model assumes a localised thermal balance, i.e. it neglects thermal advection in both the air and the sea. The atmospheric module comprises the basic elements indicated by Gill [4]. The rate of vertical exchange of heat in the ocean module is detemined via a turbulent closure module. The model response is largely determined by the specification of the three parameters: $r$, atmospheric reflection; $A$, atmospheric absorption and $\Delta T$, net temperature gradient in the atmosphere. Other parameters in the model such as wind speed, cloud cover and relative humidity are prescribed directly from representative observations. The three parameters, $r, A$ and $\Delta T$ were deduced by fitting the model results to observed $N$. Atlantic data. The derived global mean values for $r$ and $A$ were in reasonable agreement with Gill's estimates based on observations.

The coupled model is applicable for latitudes between $0^{\circ}$ and $65^{\circ} \mathrm{N}$, areas further polewards introduce particular difficulties with surface icing and with anomalous tcmperature-density functions. Generalised expressions for the annual mean sea surface $\bar{T}_{s}$ and ambient air temperature $\bar{T}_{a}$ were derived from the model simulations. These expressions indicate a dependency solely on the cosine of latitude. Corresponding expressions derived for the seasonal amplitudes $\hat{T}_{s}$ and $\hat{T}_{a}$ show a dependency on latitude, water depth and, in seas of intermediate depth (50$200 \mathrm{~m}$ ), the tidal current amplitude. This modulation of seasonal amplitudes $\hat{T}_{s}$ and $\hat{T}_{a}$ by water depths and tidal currents is substantiated by observations from the N.W. European Shelf Seas. It is the form of these generalised expressions which is of wider interest; in detailed applications some modification of the empirical coefficients might be required.

The influence of both water depth and tidal current amplitude in determining the establishment of seasonal thermal stratification was first quantified by Simpson and Hunter [16]. The present study extends this earlier result, indicating how these dynamic processes also influence ambient air temperatures. The new expressions indicate that the seasonal amplitude of the sea surface, $\hat{T}_{s}$ is of the order of $90-95 \%$ of the ambient air amplitude $\hat{T}_{a}$. However the magnitudes of both $\hat{T}_{s}$ and $\hat{T}_{a}$ are decreased by up to one fifth in areas of strong tidal currents $\left(>0.2 \mathrm{~m} \cdot \mathrm{s}^{-1}\right)$. The application of these new results to the N.W. European Shelf Seas provides an explanation as to why the seasonal amplitudes $\hat{T}_{s}$ in the seas off Galway, Liverpool and Hamburg are respectively: 3, 5 and $7{ }^{\circ} \mathrm{C}$ despite their similarity in latitude. Since it is shown how the seasonal amplitude of the ambient air is similarly modulated, the impact of the present results on coastal climate is evident.

The model was found to be relatively insensitive to small perturbations in the prescribed empirical parameters. Thus the model can be used for small-amplitude sensitivity analyses to examine, for example, the impact of changes in cloud cover, wind speed, or relative humidity or the magnitude and persistence of the impact of a single major storm. The generality of the derived expressions for $T_{s}$ and $T_{a}$ provides a simple understanding of likely conditions over a range of seas in varying latitudes and with varying water depths and tidal current amplitudes. Likewise, the present thermal ocean-atmosphere model may be usefully adopted for interdisciplinary studies including fced-back mcchanisms whereby biological and chemical parameters impact on absorption and reflection coefficients [8].

\section{APPENDICES}

\section{The Ocean Modiel}

Temperatures within the water column are calculated from the vertical dispersion equation:

$\frac{\partial}{\partial t} T=\frac{\partial}{\partial Z} K_{H} \frac{\partial T}{\partial Z}+\frac{Q(Z)}{\alpha}$

where $T$ is temperature, $K_{H}$ vertical eddy diffusivity, $Q(Z)$ the atmospheric thermal input per unit depth at level $Z, \alpha$ the thermal capacity of water, $t$ time and $Z$ the vertical axis.

The determination of $K_{H}$ is via the Mellor-Yamada level 2.5 turbulence closure model (Appendix 4). The tidal and wind-driven currents are calculated from a solution of the momentum equation

$\frac{\partial R}{\partial t}+g \nabla \zeta+i f R=\frac{\partial}{\partial Z} K q \frac{\partial R}{\partial Z}$

where $R$ is the vector current, $g$ gravity, $f$ the Coriolis parameter and $K q$ the vertical eddy viscosity, with the surface gradient $\nabla \zeta$ prescribed to produce the requisite depth-mean velocity.

\section{The Atmospheric Model}

Solar energy input, reflection, absorption and radiation

Using the notation from figure 1 , the incident solar energy per unit surface area is $S \cos \theta$ (for $\cos \theta>0$ ) 
where $S=1353 \mathrm{~W} \cdot \mathrm{m}^{-2}$ and the inclination of the sun relative to the vertical is given by:

$\cos \theta=\sin \beta \cdot \sin \lambda-\cos \beta \cdot \cos \lambda \cdot \cos \left(\chi+w_{d} l\right)$

where $w_{d}$ is the frequency of the earth's daily rotation, $\lambda$ latitude and $\chi$ longitude:

$\sin \beta=\sin \delta \cdot \sin \left(w_{a} t-\chi_{0}\right)$

$w_{a}$ is the frequency of the earth's annual rotation, declination $\delta=23.5^{\circ}$ and the 'reference' longitude $\chi_{0} \approx 80^{\circ}$ for $t$ measured relative to 1 st January. The global average of Solar energy per unit surface area is equal to $0.25 \mathrm{~S}$ as computed directly from the ratio of aspect $\pi R^{2}$ to surface area $4 \pi R^{2}$.

Gill [4] indicates that approximately $30 \%$ of this solar energy is backscattered (or reflected) at the outer edge of the atmosphere. This reflection factor, $r$, in figure $l$ is clearly a crucial parameter in determining global temperatures. In the numerical model developed here latitudinal transfer of thermal energy by ocean currents is not incorporated. Under these conditions, the following expression was found necessary to reproduce observed (N. Atlantic) air and sea surface temperature. For $\lambda \geq 65^{\circ} \mathrm{N}$ :

$r=-0.47+0.86(\cos \lambda)^{1 / 2}$

i.e. $r=0.39$ at the equator and $r=0.09$ at a latitude of $65^{\circ} \mathrm{N}$. The proportional surface area of the earth varies according to $\cos \lambda$, the surface integral of $r(\lambda) \cos \lambda$ yields a global average for $\bar{r}=0.30$, in precise agreement with Gill's estimate.

Gill [4] further indicates that $19 \%$ of the original solar energy $S$ is absorbed directly by the atmosphere before reaching the sea surface. Since the pathway length through the atmosphere of thickness $d$ is $d / \cos \theta$, the absorption at a constant rate per unit length is $A S$ per unit surface area wherever $A>\cos \theta$. For the model described here, the value $A=0.11$ was determined, this is equivalent to absorption of $15 \%$ of the area averaged incident energy of $0.25 \mathrm{~S}$ i.e. close to Gill's estimate of $19 \%$.

The radiation of heat to space from the atmosphere, $Q_{A}$, is given by Stefan's law,

i.e. $Q_{A}=\sigma\left(T_{a}-\Delta T_{a}+273\right)^{4}$

where Stefan's constant $\sigma=5.67 \times 10^{-8} \cdot \mathrm{W} \cdot \mathrm{m}^{-2} \cdot \mathrm{K}^{-4}$ and $\Delta T_{a}$ is the temperature difference between the top and bottom of the atmosphere, prescribed here as $\Delta T_{a}=$ $42.5^{\circ} \mathrm{C}$.

\section{Air-Sea thermal exchanges}

\section{Absorption and exchange by the ocean}

The heat reaching the ocean surface $S[\cos \theta(1-r)-A]$ is absorbed at a rate decreasing exponentially with the distance $Z^{1 / 2}$ below the surface. This heat is subsequently returned to the atmosphere via long wave radiation $Q_{L}$, 'evaporation' $Q_{E}$ and 'convection' $Q_{S}$ or 'sensible heat flux'. Elliott and Clarke [2] provide expressions for these (in $\mathrm{W} \cdot \mathrm{m}^{-2}$ ) as follows [4]:

$$
\begin{aligned}
Q_{L}= & 5.58 \times 10^{8}\left(T_{S}+273\right)^{4} \\
& \times\left(0.39-0.05 E_{A}^{1 / 2}\right)\left(1-0.6 C^{2}\right)
\end{aligned}
$$

where $T_{S}$ is the surface temperature in ${ }^{\circ} \mathrm{C}, E_{A}$ is the vapour pressure $(\mathrm{mb})$ at the ambient temperature and $C$ the fractional cloud cover.

$Q_{E}=4.69 \times 10^{-3} W\left(Q_{W}-Q_{A}\right)$

Where $W$ is the wind speed in $\mathrm{m} \cdot \mathrm{s}^{-1}$ and $Q_{W}$ and $Q_{A}$ the specific humidities of air at $T_{S}$ and $T_{A}$ (air temperature) respectively.

$Q_{S}=1.82 W\left(T_{S}-T_{A}\right)$

The heat lost by the sea surface is subsequently absorbed by the atmosphere, except for $0.3 Q_{L}$ which is assumed to radiate directly to space.

\section{Turbulence Model}

\section{Turbulence Model}

The Mellor Yamada level 21/2 mode (MYL 21/2, [9]) is used here to determine the values of both the vertical eddy viscosity, $K_{M}$, and vertical eddy diffusivity, $K_{H}$, coefficients. Refinements of this model described by Deleersnijder and Luyten [1] are incorporated here.

The turbulent kinetic energy (TKE or $k$ ) equation is $\frac{\partial}{\partial t}\left(\frac{q^{2}}{2}\right)=\frac{2}{\partial z}\left[K_{q} \frac{\partial}{\partial z}\left(\frac{q^{2}}{2}\right)\right]+K_{M}\left[\left(\frac{\partial u}{\partial z}\right)^{2}+\left(\frac{\partial v}{\partial z}\right)\right]+$

$$
\begin{aligned}
& K_{H} \frac{g}{\rho_{0}} \frac{\partial \rho}{\partial z}-\frac{q^{3}}{B_{1 l}}=0 \\
& \text { buoyancy } \quad \text { dissipation } \\
& \left(B_{1}=16.6\right)
\end{aligned}
$$


where the eddy coefficients are proportional to the mixing length, $l$, and associated stability functions $S_{M}$ and $S_{H}$ thus

$K_{q}=l q S_{q}=0.2 l q$

$K_{M}=l q S_{M}$

$K_{H}=l q S_{H}$

and

$k=q^{2} / 2=0.5\left(u^{\prime 2}+v^{\prime 2}+w^{\prime 2}\right)$

$u^{\prime}, v^{\prime}$ and $w^{\prime}$ are velocity fluctuations.

The mixing length, $l$, is determined from the related equation:

$\frac{\partial}{\partial t} q^{2} l=E_{1} \frac{\partial}{\partial z}\left[K_{q} \frac{\partial}{\partial z}\left(q^{2} l\right)\right]+$

$E_{1} l K_{M}\left[\left(\frac{\partial u}{\partial z}\right)^{2}+\left(\frac{\partial v}{\partial z}\right)^{2}\right]+$

$E_{1} l K_{H} \frac{g}{\rho_{0}} \frac{\partial \rho}{\partial z}-\frac{W q^{3}}{B_{1}}$

The wall proximity function $W$ is defined as

$$
W=1+\frac{E_{2} l^{2}}{\left(K_{v} L\right)^{2}}
$$

$\left.E_{2}=1.33\right)$

where $K_{V}$ is the von Karman constant $(\approx 0.4), L$ is a function of the distance to the seabed $d_{b}$ and to the sea surface $d_{s}$ thus

$L=\frac{d_{s} d_{b}}{\left(d_{s}+d_{b}\right)}$
The stability functions $S_{H}$ and $S_{M}$ are related to the BruntVaissala frequency $N$ via the parameter $G_{H}$.

$G_{H}=-\frac{l^{2}}{q^{2}}\left\{\frac{g}{\rho} \frac{\partial \rho}{\partial z}\right\}=\frac{l^{2}}{q^{2}} N^{2}$

The factor $S_{M}$ is approximated by

$$
S_{M}=\frac{0.40-3.12 G_{H}}{\left(1-40.8 G_{H}+212.2 G_{H}^{2}\right)}
$$

with prescribed limits $0.045<S_{M}<2.0$.

The function $S_{H}$ is approximated by

$S_{H}=0.49 /\left(1 .-34.7 G_{H}\right)$

with prescribed limits $0.45<S_{H}<2.5$.

The boundary conditions specilied are:

At the surface

$K_{M} \frac{\partial R}{\partial z}=\frac{\tau_{0}}{\rho}$

$\frac{\partial T}{\partial z}-\frac{Q_{0}}{\rho c}$

where the velocity $R=U+i V, \tau_{0}$ is the applied wind stress, $Q_{0}$ the surface heat exchange and $c$ the specific heat of sea water.

At the bed $K_{M} \frac{\partial R}{\partial z}=\frac{\tau_{B}}{\rho}$

$K_{H} \frac{\partial T}{\partial z}=0$

where $\tau_{B}$ is the (tidal) stress at the bed $(\rho \mathrm{k} R|R|, k$ bed stress coefficient 0.0025 )

and $q^{2} m=0$ at surface and bed.

\section{REFERENCES}

[1] Deleersnijder E., Luyten P., On the practical advantages of the quasi-equilibrium version of the Mellor and Yamada level 2.5 turbulence closure applied to marine modelling, Contribution No. 69, Institut d'Astronomie et de Géophysique Université Catholique de Louvain, Belgium (1993).

[2] Elliott A.J., Clark T., Seasonal stratification in the north-west European shelf seas, Continental Shelf Res. 11 (1991) 467492.
[3] Gent P.R., Willebrand J., McDougall T.J., McWilliams J.C., Parametcrizing eddy-induced tracer transports in ocean circulation models, J. Phys. Oceanogr. 25, 4 (1995) 463-474.

[4] Gill A.E., Atmosphere-ocean dynamics, Academic Press, Oxford (1982) p. 662.

[5] Isemer H.-J., Hasse L., The Bunker Climate Atlas of the North Atlantic Ocean, Volume 1: Observations, Springer-Verlag (1983) p. 218. 
[6] Korevaar C.G., North Sea Climate: based on observations from ships and lightvessels, Kluwer Academic Publishers, Dordrecht (1990) p. 137.

[7] Lane A., Prandle D., Inter-annual variability in the temperature of the North Sea, Continental Shelf Res. 16, 11 (1996) 1489-1507.

[8] Lovelock J.E., Kump L.R., Failure of climate regulation in a geophysiological model, Nature 369 (1994) 732-734.

[9] Mellor G.L., Yamada T., A hierarchy of turbulence closure models for planetary boundary layers, J. Atmos. Sci. (1974) 1791-1806.

[10] Nunes Vaz R.A., Simpson J.H., Turbulence closure modelling of estuarine stratification, J. Geophys. Res. 99, C8 (1994) 16143-16160.

[11] Pohlmann T., Simulating the heat storage in the North Sea with a three-dimensional circulation model, Continental Shelf Res. 16,2 (1996) 195-213.

[12] Prandle D., A modelling study of the mixing of ${ }^{137} \mathrm{Cs}$ in the seas of the European continental shelf, Philosophical Tran- sactions of the Royal Society of London, A310 (1984) 407436 .

[13] Prandle D., The scasonal eycle in sca level associated with annual temperature variations, 299-301 in Proc. Conf. Ocean and Atmosphere Pacific, 1995. NTF, Flinders Univ. Australia (1996) p. 417.

[14] Prandle D., Lane A., The annual temperature cycle in shelf seas, Continental Shelf Res. 15, 6 (1995a) 681-704.

[15] Prandle D., Lane A., Stability of the annual temperature cycle in shelf seas, J. Therm. Biol. 20, 1/2 (1995b) 111-120.

[16] Simpson J.H., Hunter J.R., Fronts in the Irish Sea, Nature 250 (1974) 404-406.

[17] Simpson J.H., Bowers D.G., The role of tidal stirring in controlling the seasonal heat cycle in shelf seas, Annales Geophysicae 2 (1984) 411-416.

[18] Taylor A.H., Stephens J.A., Seasonal and year-to-year changes in the temperatures of the English Channel and the southern North Sea 1961-76: a budget, Oceanologica Acta 6, 1 (1983) 63-72. 